\title{
Anti-thyroid Antibodies in Patients with HCV Genotype 3a: A Pilot Study
}

\author{
Sana Temuri ${ }^{1}$, Nadeem Afzal ${ }^{1 *}$, Mohammad Kashif ${ }^{1}$, Ahmed Nadeem $^{1}$, \\ Faheem Shahzad ${ }^{1}$, Waqas Latif ${ }^{2}$, Afia Abbas $^{1}$ and Tafazzul H. Mahmud ${ }^{3}$ \\ ${ }^{1}$ Department of Immunology, University of Health Sciences, Lahore, Pakistan. \\ ${ }^{2}$ Department of Biostatistics, University of Health Sciences, Lahore, Pakistan. \\ ${ }^{3}$ Department of Rheumatology and Immunology, Sheikh Zayed Hospital, Lahore, Pakistan.
}

\begin{abstract}
Authors' contributions
This work was carried out in collaboration among all the authors. Authors ST, NA and THM designed the study. Authors MK, FS and WL performed statistical analysis. Authors ST, AN and AA wrote the protocol. Authors ST, NA, MK and AN wrote first draft of manuscript. Authors FS, AN and ST managed literature searches. Authors FS, ST, WL, MK and AA also managed analyses of study and literature searches. All authors read and approved the final manuscript.
\end{abstract}

Article Information

DOI: $10.9734 / B M R J / 2016 / 28690$ Editor(s):

(1) Xing Li, Division of Biomedical Statistics and Informatics, Department of Health Sciences Research, Mayo Clinic College of Medicine, USA (2) Hung-Jen Liu, Distinguished Professor Institute of Molecular Biology, National Chung Hsing University, Taiwan. Reviewers:

(1) Jerzy Bełtowski, Medical University, Lublin, Poland. (2) Michael Grant, Memorial University of Newfoundland, Canada. (3) Mohamed Kaled A. Shambesh, Tripoli University, Medical School, Libya. (4) Nozic Darko, Military Medical Academy, Belgrade, Serbia. (5) Osama Ashry Ahmed Gheith, Mansoura University, Egypt. Complete Peer review History: http://www.sciencedomain.org/review-history/16689

Short Research Article

Received $31^{\text {st }}$ July 2016

Accepted $14^{\text {th }}$ October 2016

Published $27^{\text {th }}$ October 2016

\section{ABSTRACT}

Background: Each year, 3 to 4 million people are infected with hepatitis $\mathrm{C}$ virus (HCV) and it is the major cause of liver disease worldwide. The patient with acute HCV is often asymptomatic but can present with fatigue and jaundice. About $80 \%$ of HCV infected individual's progress to chronic state. There is an increased prevalence of HCV infection with autoimmune diseases and the most common is chronic thyroiditis, which is an inflammatory disease that leads to hypothyroidism. These individuals have an increased level of antithyroid peroxidase antibody (anti TPO-Ab).

Objectives: To determine the prevalence of antithyroid antibody (ATA) in patients of HCV genotype 3a. 
Materials and Methods: Fifty HCV infected patients with genotype $3 a$ were enrolled in this study that included 33 males and 17 females. After written informed consent, $3 \mathrm{ml}$ blood of all the patients was obtained and ATAs were detected by indirect immunofluorescence technique. These patients were divided into 3 groups, i.e. untreated 26 (52\%), mid treated 17 (34\%) and 7 (14\%) patients with hepatocellular carcinoma (HCC).

Results: Among the patients 17(51.5\%) males and 7 (41.2\%) females had ATA. Regarding different groups, $19(73.1 \%)$ of untreated, $5(29.4 \%)$ of mid treated and none of the patient in HCC group had ATA.

Conclusion: ATA was detected in a high percentage of patients with HCV genotype 3a. These antibodies were significantly higher in untreated patients as compared to mid treated and HCC patients. Further, more males had these antibodies as compared to females.

Keywords: Autoantibodies; Antithyroid antibody; ATA; HCV; genotype 3a.

\section{INTRODUCTION}

Worldwide, hepatitis $\mathrm{C}$ virus (HCV) infection is a major cause of liver disease. Acute HCV infection is commonly asymptomatic but can be accompanied by fatigue and jaundice while $75 \%-85 \%$ of $\mathrm{HCV}$ infected individual's progress to a chronic state. About 150 million people globally have chronic HCV infection [1] whereas almost $3 \%$ of the world's population is a chronic carrier of this virus. Chronic HCV infection is often characterized by steatosis, fibrosis and liver cirrhosis [2]. About $35 \%$ of chronic HCV symptomatic patients develop cirrhosis after 20 years of infection and a quarter of these cirrhotic patients develop hepatocellular carcinoma (HCC) after 30 years of infection. There are various associations of different subtypes of HCV e.g., patients with genotype 1a have severe liver disease with poor prognosis while genotype $2 a$ is found in healthy blood donors and are highly prevalent among patients with cryoglobulienmia whereas genotype 3 is associated with increased liver fibrosis and steatosis [3].

HCV infection is associated with autoimmune diseases. One of the common manifestations of $\mathrm{HCV}$ is thyroid disorders, characterized by increased level of circulating thyroid peroxidase (TPO-Ab) and thyroglobulin (Tg-Ab) antibodies $[4,5]$. Production of TPO-Ab is an initial sign of autoimmune thyroid disease (AITD) with an increased risk of hypothyroidism. Interferon suppresses tumors growth and modulates immune response. Therefore, it is used to treat various neoplastic, viral and autoimmune disorders [6]. IFN- $\alpha$ is being used successfully in clinical conditions, but due to immune enhancement or immune dysregulation, it has various side effects ranging from symptoms like influenza, severe hematological, neuropsychiatric and thyroid disorder [7].
Up to $15 \%$ of thyroid disorders have been reported in IFN- $\alpha$ treated HCV patients [6] and about $40 \%$ of them develop thyroid antibodies. The chances of thyroid dysfunctions in INFtreated HCV patients having TPO-Ab are about 50 times more as compared to $5.4 \%$ in $\mathrm{HCV}$ patients who do not have TPO-Ab [8]. Since HCV genotype $3 a$ is the most prevalent genotype in Pakistan, therefore, the present study was performed to determine the prevalence of ATA in patients of HCV genotype 3 a.

\section{MATERIALS AND METHODS}

The study was approved by the "Ethical Review Committee and Research Board" of University of Health Sciences Lahore, Pakistan.

\subsection{Patients}

The study included $50 \mathrm{HCV}$ patients with $3 \mathrm{a}$ genotype and they were recruited from the Department of Gastroentology, Sheikh Zaid Hospital, Lahore. Genotype of HCV and viral load was determined by PCR while HCC was diagnosed on liver histopathology. There were 33 $(66 \%)$ males and $17(34 \%)$ females and mean \pm SD of age of males was $39.3 \pm 9.6$ years and $33.9 \pm 8.0$ years for females. These patients were divided into 3 groups, i.e. untreated, mid treated and patients with HCC. Out of 50 patients, $52 \%$ were untreated and $34 \%$ at the mid stage of INF treatment (3 months) while $14 \%$ had HCC. Patients on multiple transfusion, autoimmune disorder and HCV patients of other genotypes were excluded from the study.

\subsection{Screening of ATA}

After an informed consent, three $\mathrm{ml}$ blood was collected from all the study subjects. After 
centrifugation, serum was separated and stored at $-80^{\circ} \mathrm{C}$. Determination of ATA was performed by indirect immunofluorescence technique using tissue labeled slides and positive control from the manufacturer (ORGENTEC Diagnostika $\mathrm{GmbH}$ ).

\subsection{Statistical Analysis}

Statistical analysis was performed using SPSS 17.0. Mean, $\pm S D$ of age, sex, treatment duration and ATA was calculated. Fisher's Exact Tests was applied to determine the $p$-value. A p-value of $\leq 0.05$ was considered as statistically significant.

\section{RESULTS}

Among the $50 \mathrm{HCV}$ patients of genotype 3a, ATA was detected in the sera of $24(48.0 \%)$ patients while $26(52.0 \%)$ did not have these antibodies. In the untreated group $19(73.1 \%)$ had ATA and in the mid treated group $5(29.4 \%)$ subjects had ATA whereas none of the subject had these antibodies in HCC group and on comparison there was statistically significant difference among the three groups $(p=0.000)$ (Table 1$)$.
Regarding gender distribution, 17 (51.5\%) males and $7(41.2 \%)$ females had ATA. In the untreated group, $15(71.4 \%)$ males and $4(80 \%)$ females and in the mid treated group $2(40.0 \%)$ males and $3(25 \%)$ females, while in HCC group none of the subject had ATA and on comparison the difference between the groups was statistically significant $(p=0.002)$ (Table 2).

\section{DISCUSSION}

In the current study, age range of the subjects was 28-46 years with the mean $\pm S D$ of age was $37.5 \pm 9.4$ years. ATA was detected in $48 \%$ of the studied population, which is not in agreement with Tran et al. [9] who documented ATA in $12.5 \%$ of $\mathrm{HCV}$ patients. The difference in the results could be due to specific genotype of HCV studied in the current study, whereas Trans et al. [9] determined ATA in HCV patients but did not consider their genotype. The present study is also not in agreement with William et al. [10], who detected ATA in $22.5 \%$ of females with recurrent pregnancy loss. The disagreement of two studies might be due todifferent clinical conditions of the subjects whose antibodies were detected.

Table 1. Number, percentage and comparison of anti-thyroid antibodies among the three groups

\begin{tabular}{lllll}
\hline \multirow{2}{*}{ Study group } & \multicolumn{3}{c}{ Anti-thyroid antibodies } & p-value \\
\cline { 2 - 4 } & Positive $\mathbf{n}(\%)$ & Negative $\mathbf{n}(\%)$ & Total $\mathbf{n}(\%)$ & \\
\hline Untreated & $19(73.1 \%)$ & $7(26.9 \%)$ & $26(100.0 \%)$ & \\
Mid treated & $5(29.4 \%)$ & $12(70.6 \%)$ & $17(100 \%)$ & $0.000 *$ \\
HCC & $0(0.0 \%)$ & $7(100.0 \%)$ & $7(100.0 \%)$ & \\
Total & $24(48.0 \%)$ & $26(52.0 \%)$ & $50(100.0 \%)$ & \\
\hline & $n=$ number, $\%=$ percentage, ${ }^{*} p \leq 0.05 ;$ statistically significant &
\end{tabular}

Table 2. Number, percentage and comparison of anti-thyroid antibodies in male and female of three groups

\begin{tabular}{|c|c|c|c|c|c|}
\hline \multirow[t]{3}{*}{ Sex } & \multicolumn{4}{|c|}{ Anti-thyroid antibodies } & \multirow[t]{3}{*}{$p$-value } \\
\hline & & Positive & Negative & \multirow[t]{2}{*}{ Total } & \\
\hline & \multicolumn{3}{|c|}{ n (\%) } & & \\
\hline \multirow{5}{*}{ Male } & Untreated & $15(71.4 \%)$ & $6(28.6 \%)$ & $21(100 \%)$ & \multirow{4}{*}{$0.002^{*}$} \\
\hline & Mid treated & $2(40.0 \%)$ & $3(60.0 \%)$ & $5(100 \%)$ & \\
\hline & $\mathrm{HCC}$ & $0(0.0 \%)$ & 7 (100.0\%) & $7(100.0 \%)$ & \\
\hline & Total & $17(51.5 \%)$ & $16(48.5 \%)$ & $33(100 \%)$ & \\
\hline & Untreated & $4(80.0 \%)$ & $1(20.0 \%)$ & $5(100.0 \%)$ & \multirow{4}{*}{0.101} \\
\hline \multirow{3}{*}{ Female } & Mid treated & $3(25.0 \%)$ & $9(75.0 \%)$ & $12(100.0 \%)$ & \\
\hline & $\mathrm{HCC}$ & $0(0.0 \%)$ & $0(0.0 \%)$ & $0(0.0 \%)$ & \\
\hline & Total & $7(41.2 \%)$ & $10(58.8 \%)$ & $17(100.0 \%)$ & \\
\hline
\end{tabular}


The current study documented $71.3 \%$ of untreated HCV patients had ATA whereas Rocco et al. [11] reported 10.3\%, Marazuela et al. [12] suggested $6.7 \%$, Carella et al. [6] detected in $10.2 \%$ and Antonelli et al. [13] documented ATA in $38 \%$ of untreated HCV patients. This disagreement could be due to the inclusion of $\mathrm{HCV}$ patients of all genotypes and large number of patients i.e., 130 patients in the study of Rocco et al. [11], Marazuela et al. [12] included 207 patients and Carella et al. [6] included 72 patients whereas in the current study only 50 patients were included. The other probable reasons for disagreement could be the sensitivity of the diagnostic technique used for the detection of ATA as ELISA was used by Marazuela et al. [12] whereas IF was used in the current study which is more sensitive. The other reason for the difference could be the specific HCV genotype of patients as well because only the current study included specific HCV genotype. Further, variability of ethnicity of the studied population could be another reason.

The present study documented ATA in $29.4 \%$ of mid treated HCV patients with genotype 3a which is in agreement with Carella et al. [14] who detected ATA in $34.6 \%$ of the mid treated HCV patients. The genotype of HCV patients was not mentioned in these studies. Increased prevalence of ATA in untreated than midtreated patients may be due the effect of treatment but it should be investigated by conducting further studies.

However, in another study Carella et al. [6] reported ATA as $13.4 \%$ in mid treated $\mathrm{HCV}$ patients which do not support the present study. This difference could be due to different diagnostic techniques as Carella et al. [6] used ELISA while present study used IF technique for the detection ATA. Yet another study by Jadali [15] documented ATA in $10.3 \%$ of the mid treated $\mathrm{HCV}$ patients. It could be due to the variation of time interval at which ATA was detected i.e. in the previous study HCV patients of 6 months treatment interval were labeled as 'mid treated' whereas in the present study subjects of 3 months treatment interval were labeled as 'mid treated'.

In the present study, $51.5 \%$ of males and $41.2 \%$ of females had ATA. Tran et al. [9], detected ATA in $31 \%$ of the females whereas they could not detect ATA in male subjects. Similarly Marazuela et al. [12], detected ATA in $14.8 \%$ of females as compared to $1 \%$ of males. The disagreement could be attributed to the difference in $\mathrm{HCV}$ genotypes as these researchers did not mention specific HCV genotype whereas current study had only HCV patients with genotype $3 a$.

High level of ATA in the untreated patients and in males suggested association of ATA with $3 a$ genotype and male subjects. Another reason for this variation could be due to the technique selected for the detection of ATA i.e. IF is more sensitive technique compared to other assays, therefore high level of ATA was detected.

\section{CONCLUSION}

ATA was detected in high percentage of $\mathrm{HCV}$ patients with genotype $3 \mathrm{a}$. These antibodies were significantly high in untreated patients as compared to mid treated and HCC patients. Further, more males had these antibodies as compared to females.

\section{COMPETING INTERESTS}

Authors have declared that no competing interests exist.

\section{REFERENCES}

1. WHO (World Health Organization). Hepatitis C fact sheet N164; 2015. Available:http://www.who.int/mediacentre/f actsheets/fs164/en/ (Accessed 11 February 2016).

2. Feitelson M. Chronic hepatitis $C$ virus infection and the pathogenesis of hepatocellular. Carcinoma. Archivum Immunologiae et Therapiae Experimentalis. 2001;49(2):65-74.

3. Rubbia-Brandt L, Fabris P, Paganin S, et al. Steatosis affects chronic hepatitis $C$ progression in a genotype specific way. Gut. 2004;53:406-12.

4. Brent GA, Larsen PR, Davies TF. Hypothyroidism and thyroiditis. In: Kronenberg HM, Melmed S, Polonsky KS, Larsen PR, eds. Williams Textbook of Endocrinology. Philadelphia, Pa: Saunders Elsevier. 2008;Chap 12.

5. Antonelli A, Ferri C, Pampana A. Thyroid disorders in chronic hepatitis C. American Journal of Medicine. 2004;117(1):10-13.

6. Carella C, Mazziotti G, Morisco F, et al. The addition of ribavirin to interferon-alpha therapy in patients with hepatitis $C$ virusrelated chronic hepatitis does not modify 
the thyroid autoantibody pattern but increases the risk of developing hypothyroidism. Journal of Clinical Endocrinology and Metabolism. 2002;146: 743-749.

7. Dumoulin FL, Leifeld L, Sauerbruch T, et al. Autoimmunity induced by interferon therapy for chronic viral hepatitis. Biomedicine \& Pharmacotherapy. 1999;53: 242-254.

8. Roti E, Minelli R, Giuberti T, et al. Multiple changes in thyroid function in patients with chronic active HCV hepatitis treated with recombinant interferon-alpha. American Journal of Medicine. 1996;101:482-487.

9. Tran A, Quaranta JF, Benzaken S, et al. High prevalence of thyroid autoantibodies in a prospective series of patients with chronic hepatitis $\mathrm{C}$ before interferon therapy. Hepatology. 1993;18:253-257.

10. William H, Kutteh MD, Deborah L, Yetman BS, et al. Increased prevalence of antithyroid antibodies identified in women with recurrent pregnancy loss but not in women undergoing assisted reproduction. Fertility and Sterility. 1998;7(5):843-848.
11. Rocco A, Gargano S, Provenzano A, et al. Incidence of autoimmune thyroiditis in interferon-alpha treated and untreated patients with chronic hepatitis $\mathrm{C}$ virus infection. Neuro Endocrinology Letters. 2001;22(1):39-44.

12. Marazuela M, Garcia-Buey L, GonzalezFernandez B, et al. Thyroid autoimmune disorders in patients with chronic hepatitis $\mathrm{C}$ before and during interferon-alpha therapy. Clinical Endocrinology. 1996;44: 635-642.

13. Antonelli A, Ferri C, Pampana A. Thyroid disorders in chronic hepatitis C. American Journal of Medicine. 2004;117(1):10-13.

14. Carella C, Mazziotti G, Morisco F, et al. Long-term outcome of interferon induced thyroid autoimmunity and prognostic influence of thyroid autoantibody pattern at the end of treatment. Journal of Clinical Endocrinology and Metabolism. 2001; 86:1925-1929.

15. Jadali Z. Autoimmune thyroid disorders in hepatitis C virus infection: Effect of interferon therapy. Indian $\mathrm{J}$ Endocrinol Metab. 2013;17(1):69-7.

(c) 2016 Temuri et al.; This is an Open Access article distributed under the terms of the Creative Commons Attribution License (http://creativecommons.org/licenses/by/4.0), which permits unrestricted use, distribution, and reproduction in any medium, provided the original work is properly cited.

Peer-review history:

The peer review history for this paper can be accessed here: http://sciencedomain.org/review-history/16689 